\title{
Editorial
}

\section{Enabling active learning}

The first conference of the Association for Learning Technology (ALT-C 94), sub-titled Enabling Active Learning, took place at the University of Hull last September. It provided a unique opportunity for lecturers, courseware developers, library staff, computing support staff, educational development staff and institutional managers to meet and discuss the effective implementation of educational technology. Space has allowed only a small selection of the papers presented to be included in this special issue of $A L T-J$ devoted mainly to the conference, but these papers address the major issues discussed.

Enabling active learning through the use of educational technology requires students to have adequate access to computers and training in using them, lecturers to have the confidence and skills necessary for using technology in their courses, and - crucially senior managers in institutions of higher education to take a proactive role in supporting innovation in teaching and learning, both financially and by adopting appropriate staffsupport policies. Real learning occurs when students are motivated, when they create, practise and synthesize, and are given feedback on their progress. Such activities require inputs, processing and outputs - hence active learning. These issues were addressed at the conference in an attempt to tease out the unique benefits of using educational technology in teaching and learning, and to identify winning strategies. However, it is not sufficient only to focus on the opportunities for successful learning. It is also necessary to consider cost: cost in terms of software development, staff training, and the investment required in hardware. Unfortunately, too few papers at the conference measured the benefits of educational innovations and the associated costs. This is a serious shortcoming when it is necessary to persuade senior management in institutions of higher education to allocate scarce resources - probably away from research - to support innovations in teaching and learning. This is a far from easy task in light of the current funding drivers in UK universities and the widely-held view that strong research leads to high-quality teaching. The latter view is supported by the recent THES analysis which suggested a strong 
correlation between a research-assessment rating of 5 and an excellent HEFCE teachingquality assessment (whatever the underlying reasons for the correlation).

We therefore need to be very clear about the real benefits of using technology in teaching and learning. Computer-aided assessment, for example, can be used not only to ensure objectivity in course-end examinations, but also to provide feedback to students on their progress. The latter is becoming increasingly difficult with the large classes now commonly found in the first year of many degree programmes. Computer-mediated communication can provide better contact between staff and students. Improved communications also provide opportunities for sharing information and teaching materials on a world-wide basis. Simulations can expose students to situations which would otherwise be difficult if not impossible to set up on account of cost, inaccessibility, scale, danger, time or ethics, and offer the potential to reduce costs through replacement of real but expensive laboratory exercises. Some of the papers in these proceedings discuss these benefits.

Clearly emerging from the conference was the enormous enthusiasm of the majority of delegates for the undoubted potential of educational technology. However, enthusiasm for it, and a deep belief in its benefits, are not sufficient. Senior management in institutions of higher education need to be persuaded with pragmatic arguments if they are to agree to go down a technological route and adequately reward staff for their efforts. One of the problems confronting the innovator in justifying technological innovation is the difficulty of estimating costs in advance of implementation, but this should not stop developers monitoring the costs, nor lecturers measuring the benefits retrospectively. Such evidence is crucial for ensuring long-term investment in the application of educational technology in teaching and learning, and for developing a mature partnership between senior management and educational technologists.

Gabriel Jacobs

Simon Heath (Conference Chair and Guest Joint Editor), University of Aberdeen 